\title{
Lateral Ground Spread at Kausaltar, Kathmandu that Appeared in the 2015 Gorkha Earthquake
}

\section{Masataka Shiga ( $\square$ shigamasataka@gmail.com )}

Institute of Industrial Science, The University of Tokyo https://orcid.org/0000-0003-2515-3962

\section{Kazuo Konagai}

International Consortium on Landslides, 138-1, Tnaka-Asukai, Sakyo, 6068226, Kyoto, Japan

\section{Rama Mohan Pokhrel}

Earth Investigation and Solution Nepal Pvt. Ltd.,Thapathali, 10769, Kathmandu, Nepal

\section{Takaaki Ikeda}

Department of Civil and Environmental Engineering, 805, Building No.1 of Mechanical Construction, Nagaoka University of Technology, 1603-1, Kami-tomioka, Nagaoka, 9402188, Niigata, Japan

\section{Research}

Keywords: 2015 Gorkha Earthquake, Kathmandu , Lateral Ground Spread , Standard Penetration Test , Multichannel Analysis of Surface Waves

Posted Date: October 11th, 2021

DOl: https://doi.org/10.21203/rs.3.rs-934173/v1

License: (c) (i) This work is licensed under a Creative Commons Attribution 4.0 International License. Read Full License 


\title{
Lateral ground spread at Kausaltar, Kathmandu that appeared in the 2015 Gorkha Earthquake
}

\author{
Masataka Shiga - Kazuo Konagai • Rama Mohan Pokhrel • \\ Takaaki Ikeda
}

Received: date / Accepted: date

\begin{abstract}
The April 25, 2015 Gorkha earthquake jolted the central region of Nepal causing extensive damage to buildings and earthen structures in both mountainous and urban areas of Nepal. Kathmandu-Bhaktapur road, one section of the Araniko Highway, crosses a small valley in the center of the Kathmandu Basin with an embankment. This embankment and adjacent area were deformed in the earthquake. To examine the cause of this ground deformation, several in-situ tests such as micro-tremor measurements, standard penetration tests (SPT), multi-channel analyses of surface waves (MASW), and $\mathrm{C}^{14}$ dating were conducted. These tests show that a silty sand layer with low plasticity has most likely been liquefied 5 to 8 meters underground. It is also shown that groundwater lowering using existing wells can decrease the liquefaction-prone area by $81 \%$.
\end{abstract}

Keywords 2015 Gorkha Earthquake · Kathmandu · Lateral Ground Spread · Standard Penetration Test · Multichannel Analysis of Surface Waves

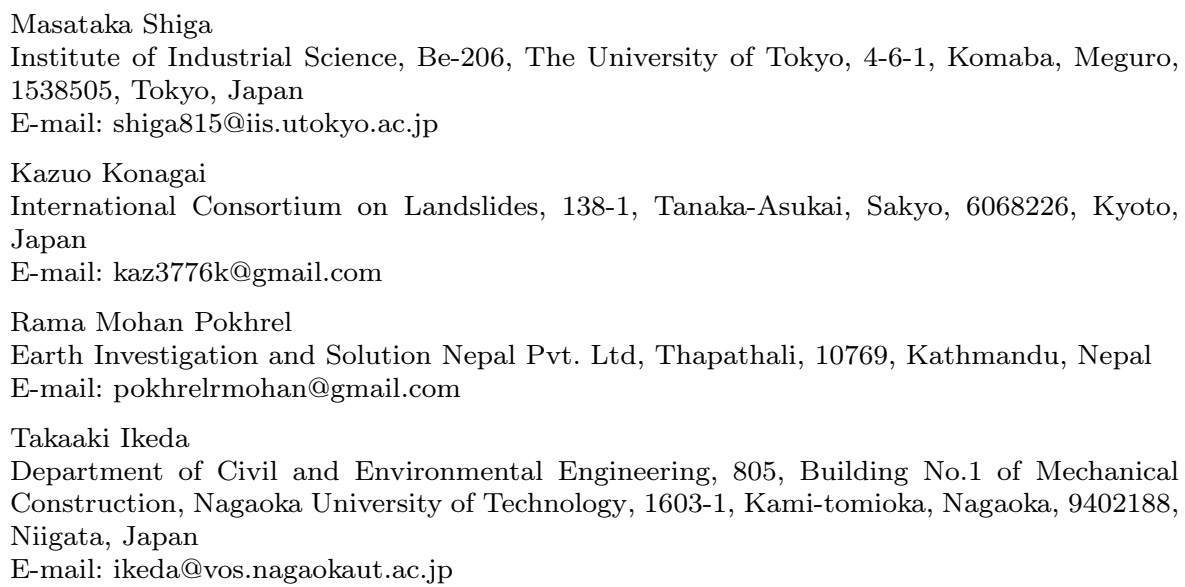




\section{INTRODUCTION}

The 2015 Nepal earthquake (Moment Magunitude, $M_{w}=7.8$ ), also called the Gorkha earthquake, was the worst natural disaster to hit Nepal since the 1934 Nepal-Bihar earthquake. The death toll and the property loss caused by this earthquake are estimated to be 8,891 and $\$ 7.1$ billion, respectively; the latter is almost equivalent to the annual national budget in Nepal (OCHA, 2015). The earthquake had caused severe damage to buildings and ground in the Kathmandu basin as shown in Figure 1. Some researchers attribute this damage to the soft and thick basin deposit. A deep borehole log (Sakai et al., 2000), shows that a weak clay layer called Kalimati formation lies 15 to 40 meters underground. A series of magnetostratigraphic and paleontological observations revealed that several lacustrine formations stack one on the other $600 \mathrm{~m}$ thick in the basin (Katel et al., 1996).

[Fig. 1 about here.]

\section{STUDY AREA}

Kausaltar, about $2 \mathrm{~km}$ southeast of the Tribhuvan International Airport of Kathmandu, is a residential area spreading over terraces constituting the upper part of the sedimentary sequence of the Kathmandu Valley. An about 500 meters stretch of the Kathmandu-Bhaktapur Road, a section of the Araniko Highway, crosses diagonally a small shallow swampy valley down-cutting the terrace (Figure 2 ).

200 to 400 meters long fissures associated with vertical ground offsets appeared diagonally across this road. These fissures run almost parallel to each other trending in NEE to SWW direction and slightly bend to the east after crossing the road. These fissures associated with vertical offsets indicate that the soil mass on the northwestern side of them slumped as a whole, and moved slightly towards the shallow and swampy valley, which runs almost parallel to these fissures. These fissures die out beyond their eastern and western ends and were about 400 meters long at the longest. The longest fissure bordering the southeastern end of the deformed area was accompanied by the largest vertical offset reaching 2 meters. There were other shorter fissures that appeared on the other side of the valley, and both sides of the valley seem to have moved against each other causing the middle part of the highway section to be slightly bent up (Konagai et al., 2015).

There are some previous investigations about these fissures. They include a report from the Japan International Cooperation Agency (JICA, 2015), which agency has been supporting the restoration of the damaged section of the Araniko Highway, and a report from the Geotechnical Extreme Events Reconnaissance, USA (Hashash et al., 2015). These reports have shown important clues to discuss the causes of this ground deformation; the clues include sand-filled fissures (Figure 3), the presence of shallow organic soil layer, 
etc. However, they just provide us with information point-wise. To cover a much wider extent of the deformed ground, we conducted several in-situ tests such as micro-tremor measurements, standard penetration tests, multi-channel analyses of surface waves, and $\mathrm{C}^{14}$ dating.

[Fig. 2 about here.]

[Fig. 3 about here.]

\section{METHODOLOGY}

To examine the sub-surface ground structure, we performed a series of field tests. Firstly, micro-tremor measurements were conducted in Kausaltar and the downtown area of Kathmandu near the "Kathmandu, Nepal observatory of the United States Geological Survey" (KATNP, hereafter) at $27.7124^{\circ} \mathrm{N}$, $85.3156^{\circ} \mathrm{E}$. We measured three orthogonal components of ambient ground motion velocities at $100 \mathrm{~Hz}$ with seismographs (Tokyo Sokushin CV-374AV, whose reliable frequency range is from 0.1 to $100 \mathrm{~Hz}$ ) at 7 points on the deformed ground on the northwestern side of the highway (BH-1 and BH-3 8 in Figure 2), 3 points on the adjacent intact ground (BH-9, MT-1, and MT-2 in Figure 2) and 4 points next to KATNP observatory. At each location, the ratio between the Fourier amplitude spectra of the horizontal $(H)$ to vertical $(V)$ components of ambient ground vibrations was obtained. This $H / V$ ratio has been related, by previous researches such as Nakamura (1989); Tokimatsu and Miyadera (1992); Lermo and Francisco (1994), to Rayleigh-type surface wave ellipticity that represents intrinsic nature of the underlying layered soil medium. Particularly when there exists a sharp contrast in terms of impedance between the surface soft soil and the underlying stiff bed stratum, a clear peak in the $H / V$ spectrum can appear at the fundamental frequency of the surface layer (Tokimatsu and Miyadera, 1992).

Secondly, Multi-channel Analyses of Surface Waves (MASW) were performed along two lines on the deformed ground to evaluate the stiffness profile of the shallow ground. It is known that Rayleigh waves, which have a dispersion relationship, predominate when vibrations are artificially generated in the surface soil. Rayleigh waves reflect the mechanical nature of deeper soils of the ground (Park et al., 1999). Consequently, shear-wave velocity $\left(v_{s}\right)$ distributions below the surveyed area can be deduced after a series of MASW tests.

Thirdly, we conduct Standard Penetration Tests (SPT) at 5 boreholes based on JIS A1219 (Association, 2013) . At each borehole, a thick-walled sample tube is driven down by blows from a slide hammer with a mass of 63.5 $\mathrm{kg}$ falling through a height of $760 \mathrm{~mm}$. Skimming the first $15 \mathrm{~cm}$ of penetration, the number of blows ( $\mathrm{N}$ value) required for the second, third and fourth $10 \mathrm{~cm}$ of penetration are counted. 
Finally, $\mathrm{C}^{14}$ dating is conducted to determine the age of soils samples obtained from the boreholes and a trench, which was by chance excavated for constructing a retaining wall near the shallow swampy valley (see its location in Figure 2 ).

\section{RESULTS AND DISCUSSION}

\subsection{VIBRATION CHARACTERISTICS}

Micro-tremors were measured at 7 locations in the most seriously deformed area, 3 locations in its surrounding areas in Kausaltar, and 4 more locations near the KATNP Observatory in Kathmandu. This observatory is located about $6 \mathrm{~km}$ northwest of Kausaltar, and the strong ground motion of the mainshock was recorded at this observatory. $H / V$ spectra, namely horizontal versus vertical component ratios are obtained at all locations. Figure 4 shows the computed $H / V$ spectra at each location. This figure indicates that all $H / V$ spectra show relatively large values in a frequency range lower than 1 $\mathrm{Hz}$, which may reflect the presence of an extremely thick lacustrine deposit of the Paleo-Kathmandu lake. However, for the higher frequency range, nothing seems to assure the difference between the deformed and intact grounds.

Figure 5 shows the variation of amplitude ratio in the frequency domain with the average Fourier amplitude spectrum of microtremors near the KATNP observatory as the reference. The red and black lines are for the deformed and intact grounds in Kausaltar, respectively. The spike that appears at $40 \mathrm{~Hz}$ is probably due to an unexpected external and/or internal noise of the seismograph. It is perhaps premature to deduce the basic nature of the ground at Kausaltar only from Figure 5 without knowing the real picture of the source of ambient micro-tremors in the basin. However, when compared with the area near the KATNP observatory, the ground at Kausaltar is considered to be more easily shaken over the frequency range larger than $2 \mathrm{~Hz}$. This tendency is clearer for the seriously deformed area.

\subsection{SUBSURFACE STRUCTURE}

\subsubsection{Multi-channel Analysis of Surface Wave (MASW)}

We conducted MASW to evaluate the stiffness profile of the shallow ground along lines No. 1 and No.2 inFigure 2 . Line 1 extends over a $70 \mathrm{~m}$ stretch in the transverse direction with respect to the highway, and Line 2 extends over a 206 meters distance along the highway. Both lines cross diagonally several ground fissures. Figure 6 shows the estimated spatial distribution of shear wave velocity $\left(V_{s}\right)$. Colder colors show higher shear wave velocity values, $V_{s}$, while warmer colors show lower $V_{s}$ values. Looking at the shallow part of the ground in Figure 6, a low $V_{s}$ zone (1) spreads 3 to 5 meters underground over 
the entire stretch of both Lines 1 and 2 . One more zone of low $V_{s}$ values (2) can be seen 5 to 10 meters underground on the detached soil mass side. These two layers of low $V_{s}$ can be considered as possible causes.

[Fig. 4 about here.]

[Fig. 5 about here.]

[Fig. 6 about here.]

\subsubsection{In-situ Sounding Tests}

To examine the natures of weak soil layers found in the MASW, we drilled 5 boreholes in the ground to a depth of 10 meters for BH-5, 7, and 9, and 15 meters for BH-6 and 8, respectively.Figure 7 shows the soil properties and SPT $\mathrm{N}$-value distribution for all boreholes. SPT N-value represents the hardness of the soil layer. At the almost entire depth of BH-7, BH-8, and BH-9, N-value is 10 or smaller, which boreholes are closer to the swampy valley than the others. Groundwater levels in BH-5, BH-6, BH-7, and BH-8, which are shown by blue broken lines in Figure 7, lie between 4.4 to 7.3 meters underground. Groundwater level couldn't be observed in BH-9. We also found organic soils from the extracted core samples above the groundwater level. The depths of these organic soils are consistent with the depths of the upper low $V_{s}$ layers.

A silty sand layer spreads at almost the same depth as that of the deeper low $V_{s}$ layer. Some part of this layer is below the aquifer level. Several samples below the organic layer were found including very thin tabular sand-filled fissures suggesting the presence of a liquefiable layer beneath them.

\subsection{3 $C^{14}$ dating}

We conducted carbon 14 dating for the soil samples taken from the trench and the 3 boreholes. The samples from these boreholes show that there is a weak organic soil layer 2 to 5 meters underground. Table. 1 shows the result of the $\mathrm{C}^{14}$ dating. The estimated age varies from $\mathrm{BC} 9,300$ to $\mathrm{BC} 13,100$. These ages overlap the age when the paleo-Kathmandu lake was drying around BC10,000 (Sakai et al., 2016). This fact indicates that two low shear wave velocity layers constitute the upper part of the sedimentary sequence when the paleo-Katmandu lake was emptying.

\subsection{SPATIAL ELEVATION MODELING OF CASUAL LAYERS WITH GIS}

The difference between the upper surface of the aquifer and the lower surface of the silty sand layer was obtained at each borehole and each existing well, and its spatial distribution was interpolated over the entire stretch of the target 
area (Figure 8 ). Though groundwater level can differ from time to time, it is noted that the orange area where the silty sand is immersed in the aquifer overlaps the area of lateral spread in association with vertical ground offsets (as shown in the white lines).

Given all these findings, the water-saturated silty sand, which may have been weakened and/or liquefied in the earthquake, is considered to be the most suspicious culprit of the lateral ground spread.

[Fig. 7 about here.]

[Table 1 about here.]

[Fig. 8 about here.]

\subsection{EFFECT OF GROUND WATER LOWERING AT EXISTING LOCAL WELLS}

To prevent the water-saturated silty sand layer from softening in a future earthquake, we propose the groundwater lowering using local wells as an effective measure. The Google Earth satellite image obtained on November $11^{t h}, 2015$ shows that there are a total of 70 houses in the deformed area; all these houses presumably have wells. Adding 14 candidate locations on open areas for drilling new wells, a total of 84 wells are assumed to be there in the deformed area. Figure 9 shows again the difference between the upper surface of the aquifer and the lower surface of the silty sand layer. In this figure, the upper surface of the aquifer is assumed to be 1.75 meters higher that the observed one just to be on the safe side of discussion considering the seasonal fluctuation of the groundwater level. Unless otherwise noted, the quantities in the following equations are shown in meter $(\mathrm{m})$ and second $(\mathrm{s})$.

Copper-Jacob Method (Cooper and Jacob, 1946) is used herein to estimate the reduction in an unconfined aquifer's saturated thickness $h$ resulting from groundwater withdrawal by a pumping well, which is given by:

$$
\ln \frac{R}{r}=\frac{2 \pi h_{p} k}{Q}\left(h_{b}-h\right)
$$

where, $r$ is the radial distance between the center of each well and a certain location where the unconfined aquifer's saturated thickness $h$ is reached during continuous pumping, $h_{p}$ is the equilibrium water level in the well during pumping, $Q$ is the volume of water pumped per unit time, $h_{b}$ is the equilibrium water level before pumping starts, $R$ is the influence radius beyond which the water level converges on the initial water level and is given by:

$$
R=3000 s \sqrt{k}
$$


where, $s$ is the height of drawdown(Kyrieleis and Sichardt (1930) ). Based on Creager et al. (1945), the permeability coefficient $k$ is empirically given by:

$$
k=0.0034 D_{20}^{2.2954}
$$

with $D_{20}(\mathrm{~mm})$ as the particle size for which $20 \%$ of the material is finer, which is set at $0.039 \mathrm{~mm}$ in this analysis. As shown in Figure 10 , when $4.2 \mathrm{~m}^{3} /$ day of water is withdrawn at each well, the area overlying the water-saturated silty sand layer decreases from $2.9 \times 10^{4} \mathrm{~m}^{2}$ to $5.6 \times 10^{3} \mathrm{~m}^{2}$.

[Fig. 9 about here.]

[Fig. 10 about here.]

\section{CONCLUSION}

A lateral ground spread associated with 200 to 400 meters long fissures crossing diagonally an embankment section of the Kathmandu-Bhaktapur Road and its surrounding residential area appeared in the 2015 Gorkha Earthquake in a thick lacustrine deposit in Kathmandu Basin. To look into what caused the lateral spread, a series of in-situ tests were conducted.

$H / V$ spectra obtained through microtremor measurements did not show any marked difference between the seriously and less seriously deformed areas in Kausaltar. However, when microtremors at these areas were compared with those in the downtown area of Kathmandu near the KATNP observatory, the ground at Kausaltar seems to be more liable to be shaken over a frequency range larger than $2 \mathrm{~Hz}$. Multi-channel Analyses of Surface Waves revealed the presence of two soft soil layers. One spreads 2 to 4 meters underground over the entire stretch of the target area, while the other spreads 5 meters underground mostly on the lower side of the swath of ground fissures. Standard Penetration Tests (SPT), and $\mathrm{C}^{14}$ dating revealed that there exists a weak organic soil layer 2 to 5 meters underground, while the other soft soil layer 5 to 8 meters underground was silty sand. Examining groundwater levels at existing wells and boreholes that we drilled, it was found that the soil mass detached along the fissures seems to overlie the water-saturated silty sand layer, which might have liquefied in the earthquake.

One of the possible measures to cope with the concern about a future big earthquake that can hit Kathmandu Basin will be groundwater withdrawal. Assuming that every house in Kausalter presumably has a private well and that another 14 new wells can be drilled in open areas in Kausalter, a total of 84 wells in Kausalter can be used to lower the unconfined groundwater level. It was found through a numerical examination using Copper-Jacob Method that the area overlying the saturated silty sand layer can decrease by $81 \%$ when $4.2 \mathrm{~m}^{3}$ /day of water is withdrawn from each well. Further studies will be necessary regarding if the proposed measure is worth the cost, how the withdrawn water can be used, etc. 
6 List of abbreviations

[Table 2 about here.]

\section{Availability of data and materials}

The datasets used and/or analysed during the current study are available from the corresponding author on reasonable request.

\section{Competing interests}

The authors declare that they have no competing interests.

\section{Funding}

The authors are indebted to the Japan Society for the Promotion of Science, which has provided the authors with financial support for conducting field surveys in Nepal; the support is "Detection of hidden unstable landslide masses still perched atop mountain slopes, and their risk assessment," Overseas Academic Research, the Japan Society for the Promotion of Science, No. 16H02744 (Leader: Kazuo Konagai).

\section{Authors' contributions}

M.S. analyzed and interpreted all of the site-investigation data regarding the borehole log and micro-tremors. K.K. showed the overall direction of the study and supervised the findings of this work. R.M.P made a geological interpretation of the data. T.K. made a consideration of vibration characteristics. All authors read and approved the final manuscript.

\section{Acknowledgments}

Special thanks go to Mr. Masashi Ogawa, Ambassador, Mr. Shinya Machida, Counsellor, and Mr. Makoto Oyama, First Secretary at the Embassy of Japan, Kathmandu, Nepal, Professor Tara Nidhi Bhattarai, and Prof. Danda Pani Adhikari, Department of Geology, Tribhuvan University, Dr. Akira Nakamura, Mr. Kazuki Shimada, and Mr. Sanumasa Kazui, Infrastructure and Peacebuilding Department, Japan International Cooperation Agency who have kindly provided the authors with important pieces of information regarding damage caused by the 2015 Gorkha Earthquake as well as every convenience for field surveys. The authors wish to acknowledge Dr. Minoru Yoneda, Dr. 
Takayuki Omori, and Mr. Hiromasa Ozaki, Laboratory of Radiocarbon Dating, The University of Tokyo for providing them with ages of soil samples containing organic matters through carbon 14 dating. The authors also would like to express their sincere gratitude to Mr. Shogo Aoyama for conducting the borehole drilling and a series of physical tests. Finally, the authors wish to thank the great help given by Dr. Alessandra Mayumi Nakata Kaiami, Mr. Hikaru Tomita, and Mr. Bhandari Basant in the field investigations.

\section{References}

Angster S, Fielding EJ, Wesnousky S, Pierce I, Chamlagain D, Gautam D, Upreti BN, Kumahara Y, Nakata T (2015) "Field Reconnaissance after the 25 April 2015 M 78 Gorkha Earthquake 85:1506-1513

Association JS (2013) JIS A1219:2013 Method for standard penetration test . In: Japanese Industrial Standards

Cooper HH, Jacob CE (1946) A generalized graphical method for evaluating formation constants and summarizing well field history. Am Geophys Union Trans 27:526-534

Creager WP, Justin JD, Hinds J (1945) Engineering for dams, Earth, Rock-fill, Steel and Timber Dams. III pp 648-649

Hashash Y, Tiwari B, Moss R, Asimaki D, Clahan K, Kieffer D, Dreger D, MacDonald A, Madugo C, Mason B, Pehlivan M, Rayamajhi D, Acharya I, Adhikari B (2015) Geotechnical Field Reconnaissance: Gorkha (Nepal) Earthquake of April 252015 and Related Shaking Sequence

JICA (2015) The Project on Urban Transport Improvement for Kathmandu Valley in Federal Democratic Republic of Nepal. URL https:// openjicareport.jica.go.jp/pdf/12289674.pdf

Katel TP, Upreti BN, Pokharel GS (1996) Engineering properties of fine grained soils of Kathmandu Valley. Journal of Nepal Geological Society 13:121-138

Konagai K, Pokhrel RM, Matsubara H, Shiga M (2015) Geotechnical aspect of the damage caused by the April 25th. JSCE Journal of Disaster FactSheets

Kyrieleis W, Sichardt W (1930) Grundwasserabsenkung bei Fundierungsarbeiten. Julius Springer

Lermo J, Francisco J (1994) Chávez-García; Are microtremors useful in site response evaluation. Bulletin of the Seismological Society of America 84(5):1350-1364

Nakamura Y (1989) A method for dynamic characteristics estimation of subsurface using microtremor on the ground surface. Quarterly Report of Railway Technical Research Institute 30:25-33

OCHA (2015) Humanitarian Bulletin Nepal Earthquake Issue 04 (Final Issue). URL https://reliefweb.int/sites/reliefweb.int/files/resources/ NepalEarthquakeHumanitarianBulletinNo4\%28Sept2015\%29_Final.pdf

Park C, Miller R, Xia J (1999) Multichannel analysis of surface waves (MASW). Geophysics 64, DOI 10.1190/1.1444590 
Sakai H, Fujii R, Kuwahara Y, Noi H (2000) Climatic Changes and Tectonic Events Recorded in the Paleo-Kathmandu Lake Sediment. Journal of Geography 109(5):759-769

Sakai H, Fujii R, Sugimoto M (2016) Two times lowering of lake water at around 48 and $38 \mathrm{ka}$, caused by possible earthquakes, recorded in the PaleoKathmandu lake, central Nepal Himalaya. Earth Planets Space 68:31-31

Tokimatsu K, Miyadera Y (1992) Characteristics of Rayleigh waves in microtremors and their relation to underground structures. Journal of Structure Construction Engineering 439:81-87 


\section{List of Figures}

1 1. Interferogramm showing fringes induced by ground displacement along the line of sight in Kathmandu Basin (Angster et al.,



2 Ground offsets that appeared in Area 2 and locations of measurement by several investigation teams (Konagai et al., 2015; JICA, 2015; Hashash et al., 2015) with overlaid on aerial image from Google Earth Pro . . . . . . . . . . . . . . . . . .

3 3. Sand-filled fissure that appeared on a wall of Trench-1 excavated by Angster et al. (2015) . . . . . . . . . . . . . . . 13

4 Micro-tremor $H / V$ spectra at observation sites undeformed area, less-deformed area in Kausaltar, and near the KATNP observatory ...................... . . 14

5 Variation of frequency-domain amplitude ratio at $\mathrm{BH}-3$ and MT-2 with the Fourier amplitude spectrum of the microtremor observed at USGS-3 as the reference . . . . . . . . . . . . . 15

6 Spatial distribution of $V_{s}$ obtained through multi-channel analyses of surface waves . . . . . . . . . . . . . . . 16

7 Soil Classifications and SPT N-value distributions at 5 boreholes. Blue dotted line shows the initial water level of each boreholeafter reaching that depth. . . . . . . . . . 17

8 Difference between the upper surface of the aquifer and the upper surface of the silty sand layer in Kausalter (Area 2 in Figure 1 ) . . . . . . . . . . . . . . . . . . . . 18

9 Difference between the upper surface of the aquifer and the lower surface of the silty sand layer in Kausalter (before lowering groundwater level) . . . . . . . . . . . . . . .

10 Difference between the upper surface of the aquifer and the lower surface of the silty sand layer in Kausalter (After lowering groundwater level) . . . . . . . . . . . . . 


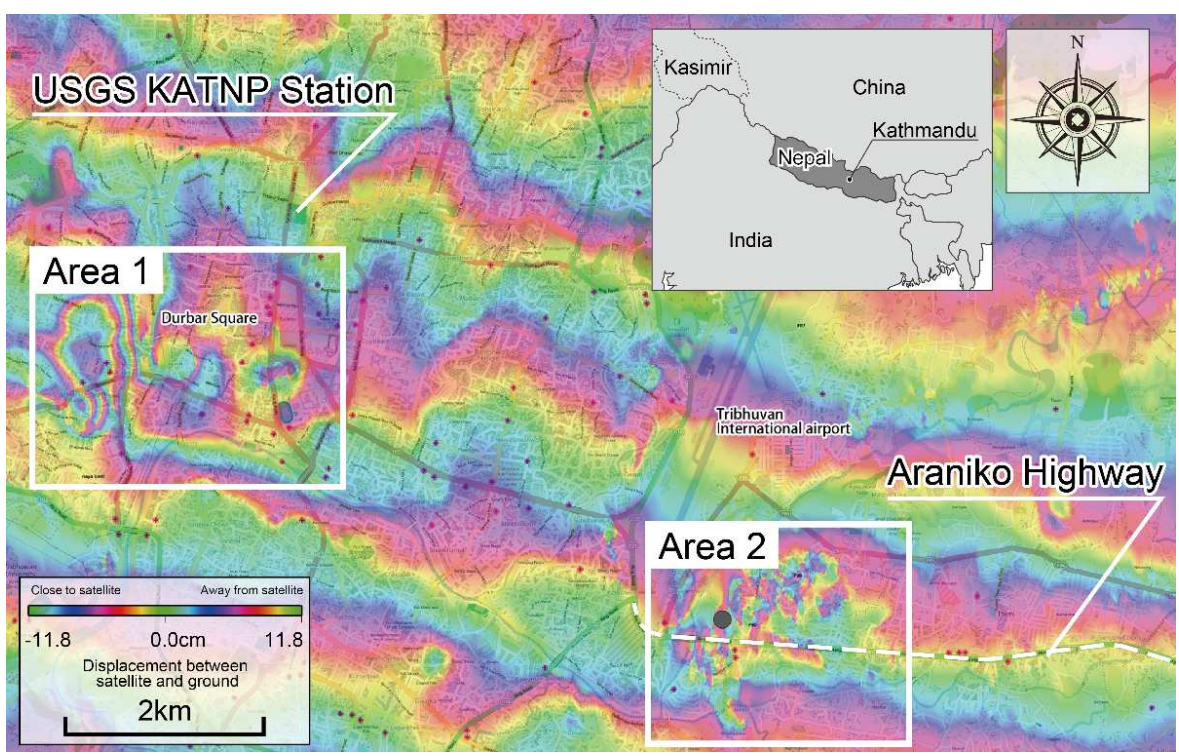

Fig. 1 1. Interferogramm showing fringes induced by ground displacement along the line of sight in Kathmandu Basin (Angster et al., 2015) 


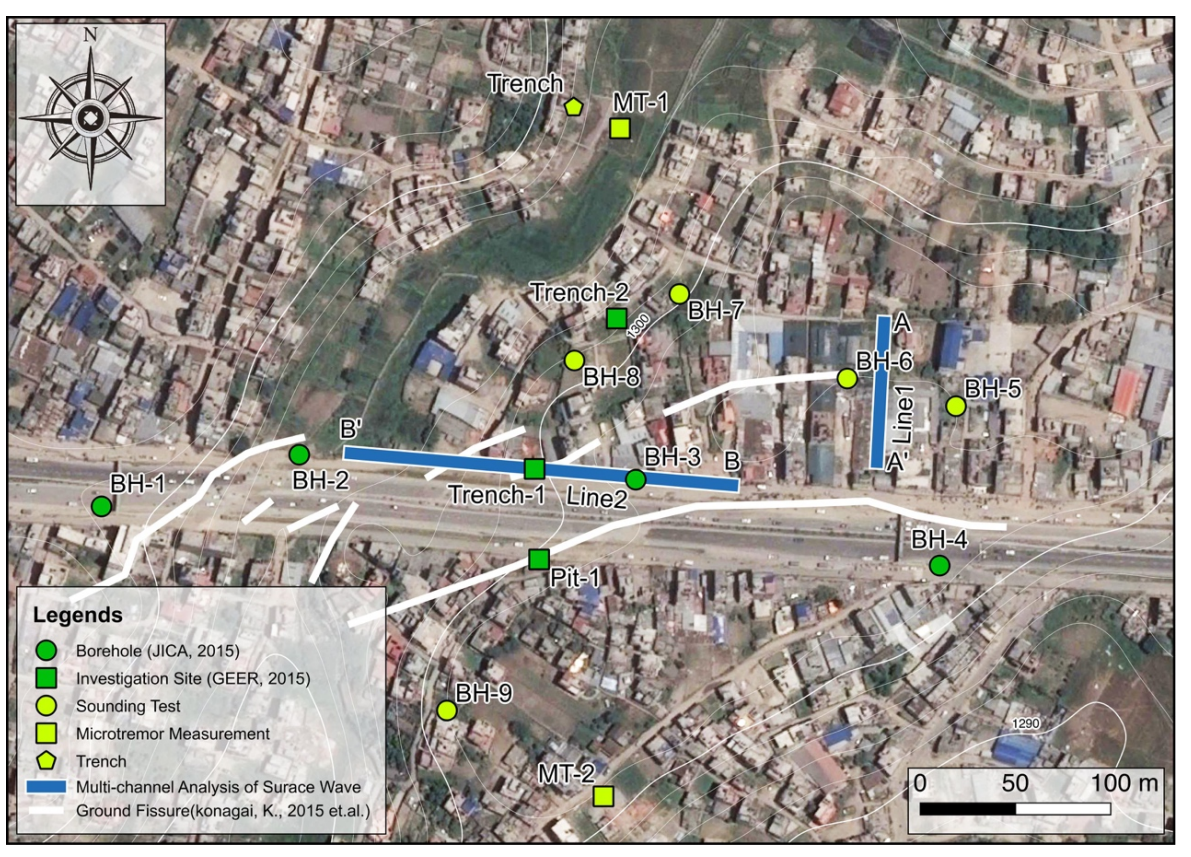

Fig. 2 Ground offsets that appeared in Area 2 and locations of measurement by several investigation teams (Konagai et al., 2015; JICA, 2015; Hashash et al., 2015) with overlaid on aerial image from Google Earth Pro 


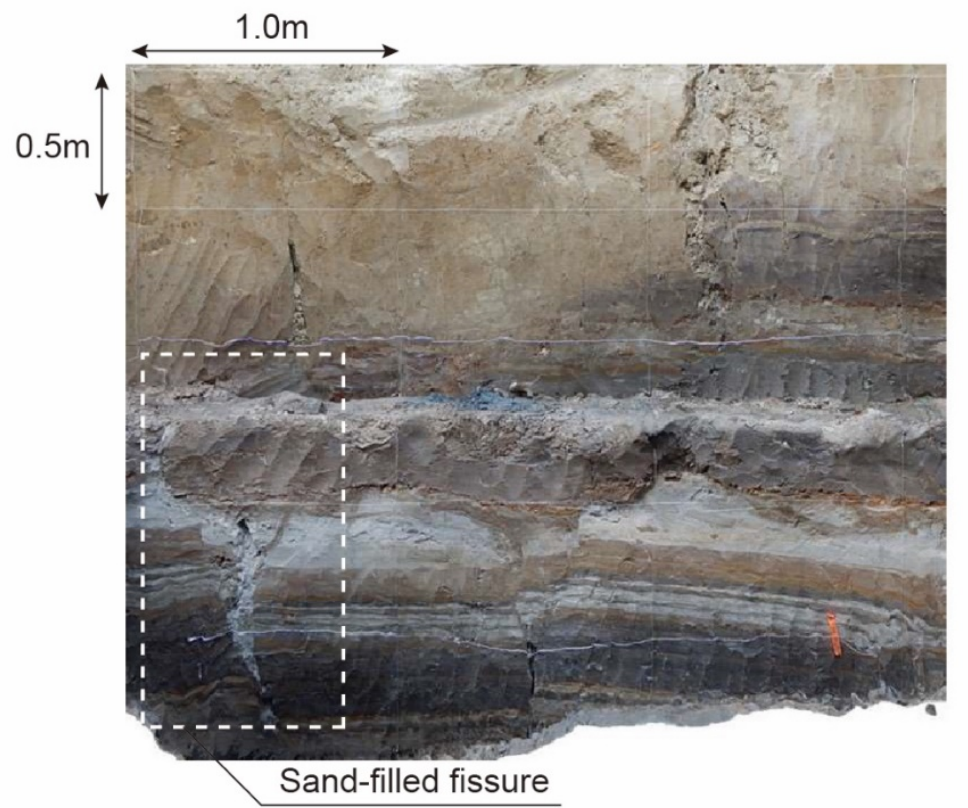

Fig. 3 3. Sand-filled fissure that appeared on a wall of Trench-1 excavated by Angster et al. (2015) 

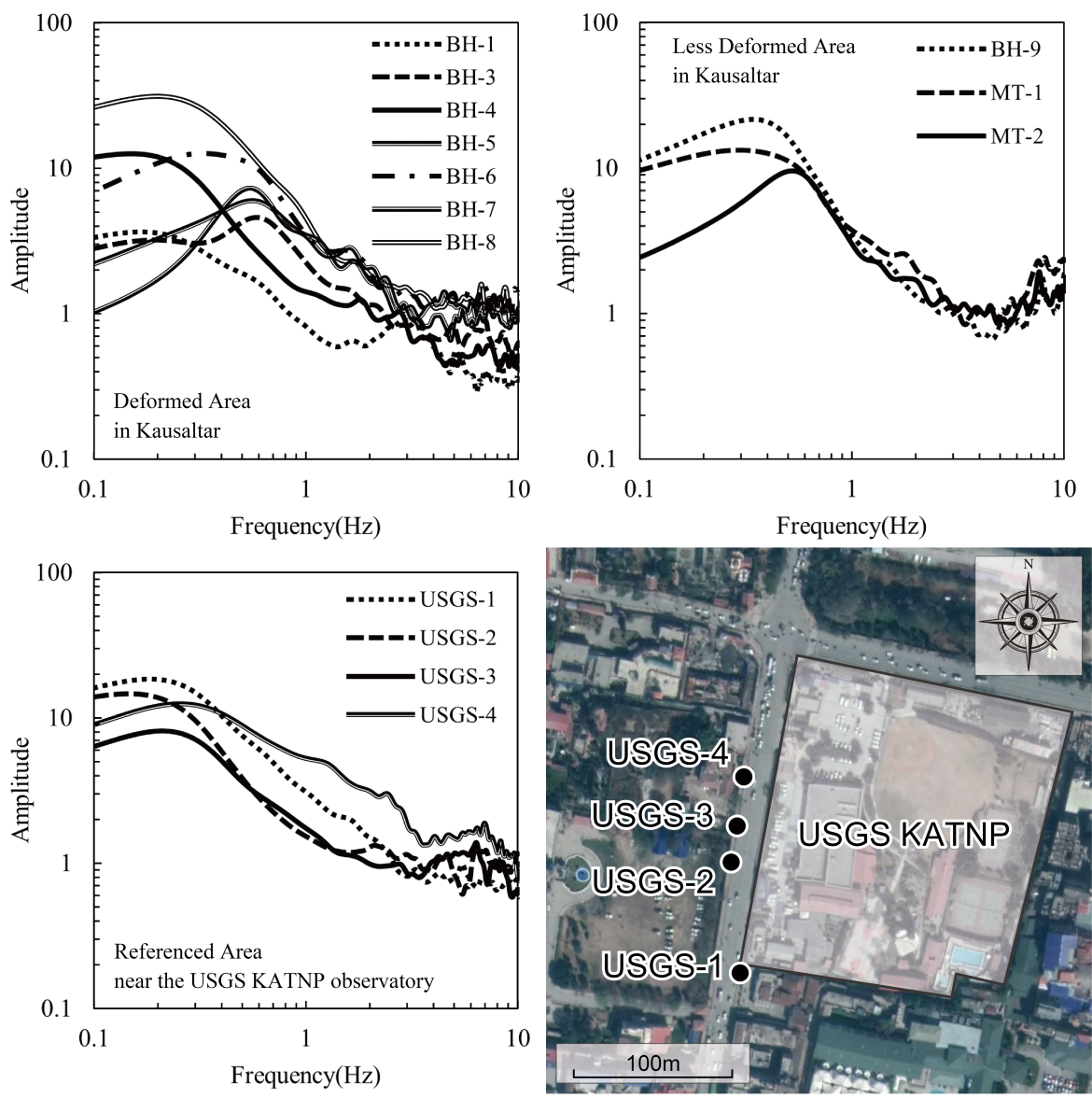

Fig. 4 Micro-tremor $H / V$ spectra at observation sites undeformed area, less-deformed area in Kausaltar, and near the KATNP observatory 


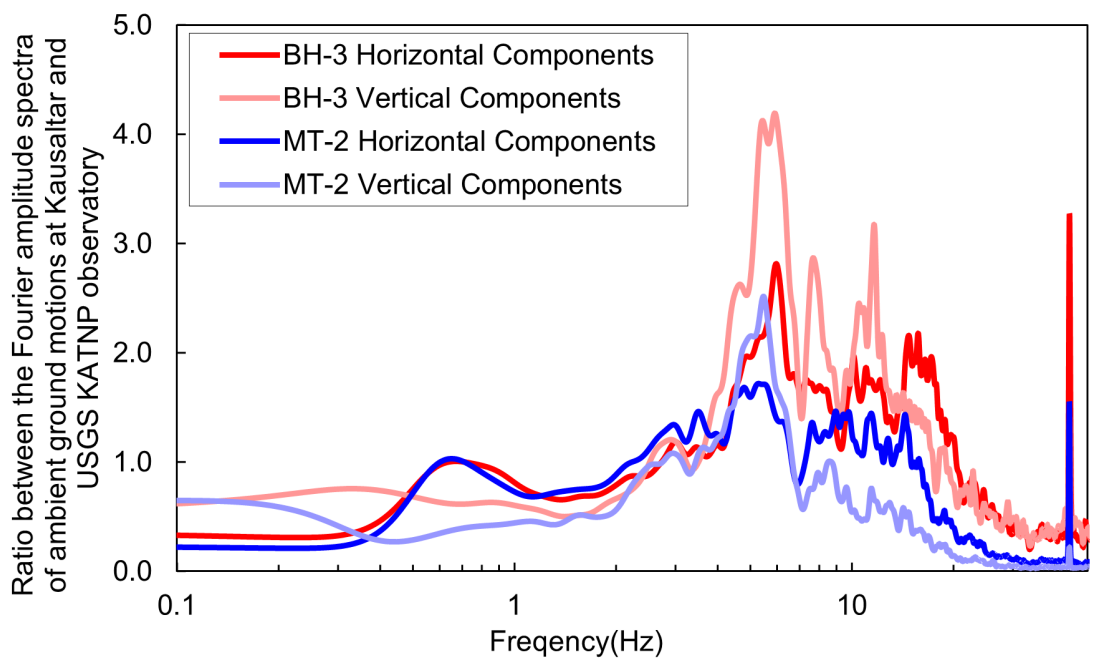

Fig. 5 Variation of frequency-domain amplitude ratio at BH-3 and MT-2 with the Fourier amplitude spectrum of the microtremor observed at USGS-3 as the reference 

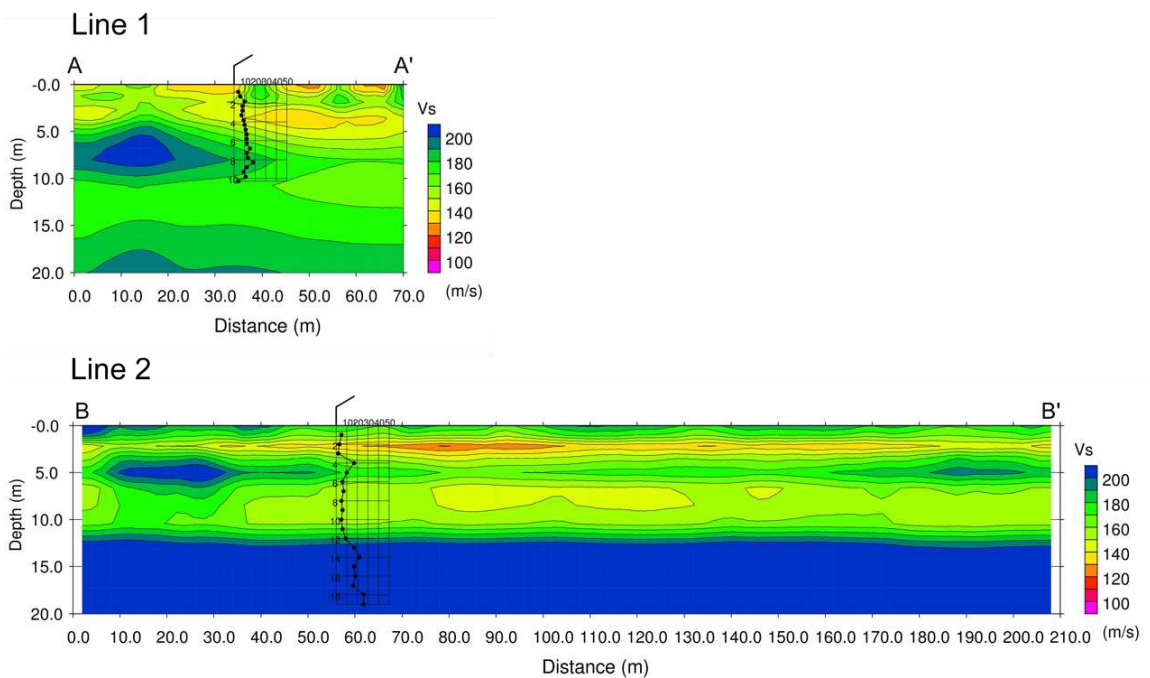

Fig. 6 Spatial distribution of $V_{s}$ obtained through multi-channel analyses of surface waves 


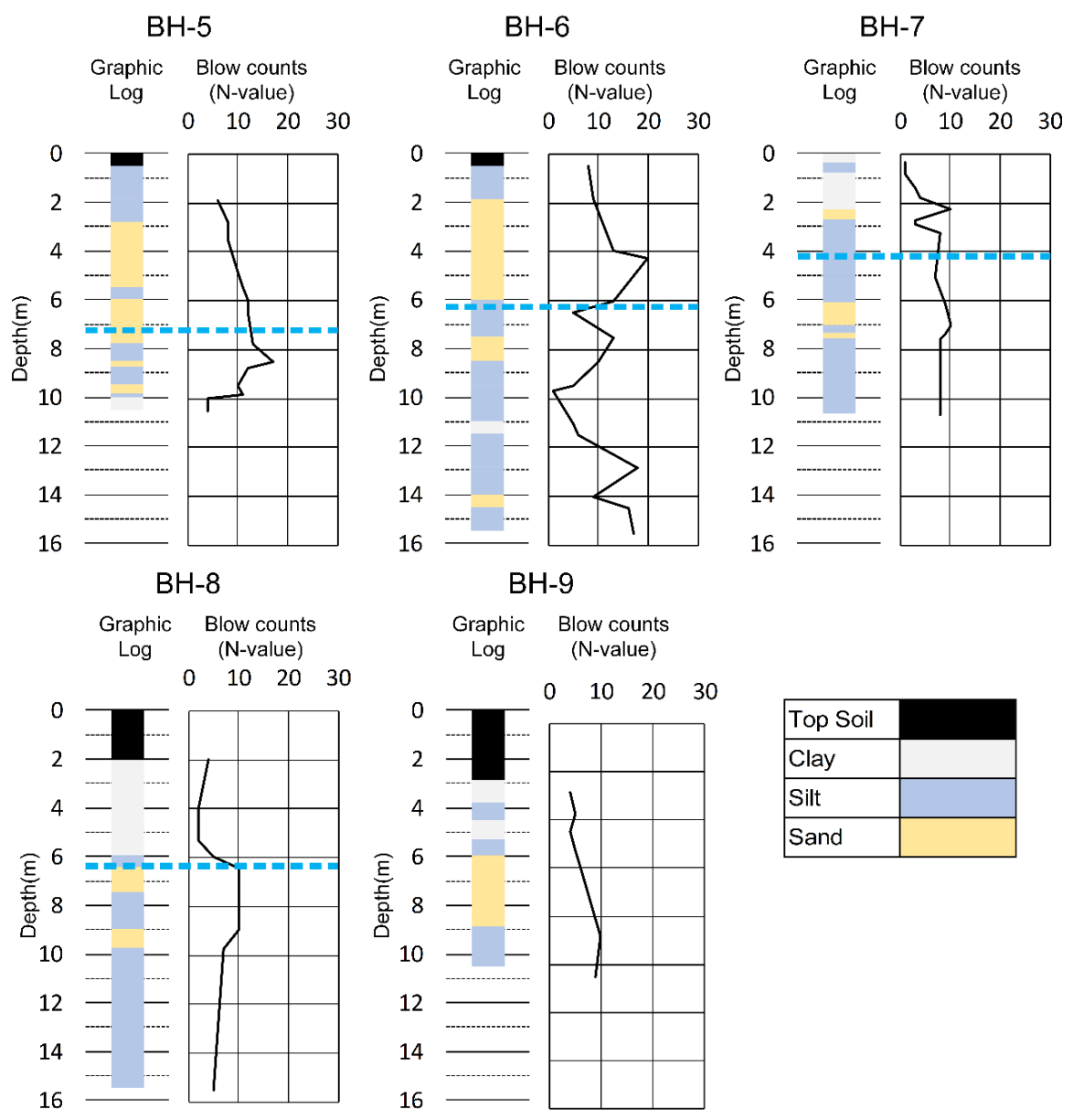

Fig. 7 Soil Classifications and SPT N-value distributions at 5 boreholes. Blue dotted line shows the initial water level of each boreholeafter reaching that depth. 


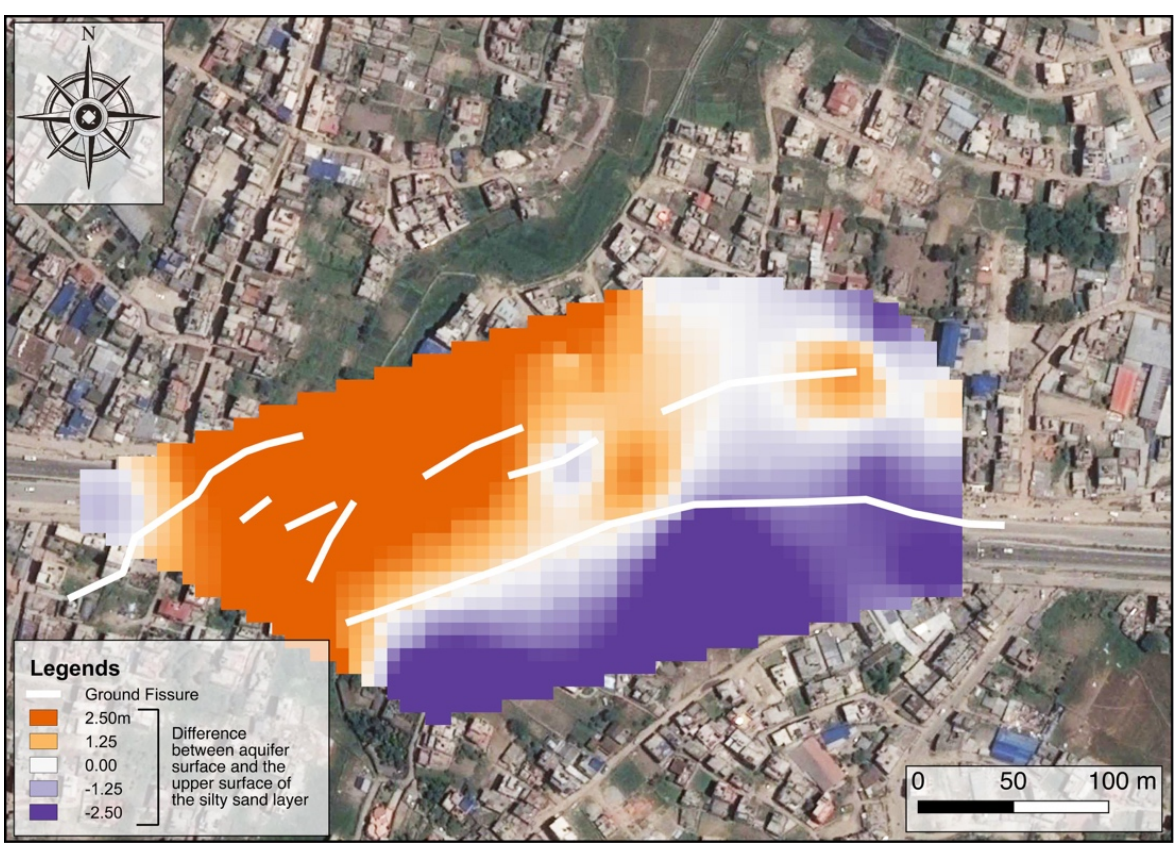

Fig. 8 Difference between the upper surface of the aquifer and the upper surface of the silty sand layer in Kausalter (Area 2 in Figure 1 ) 


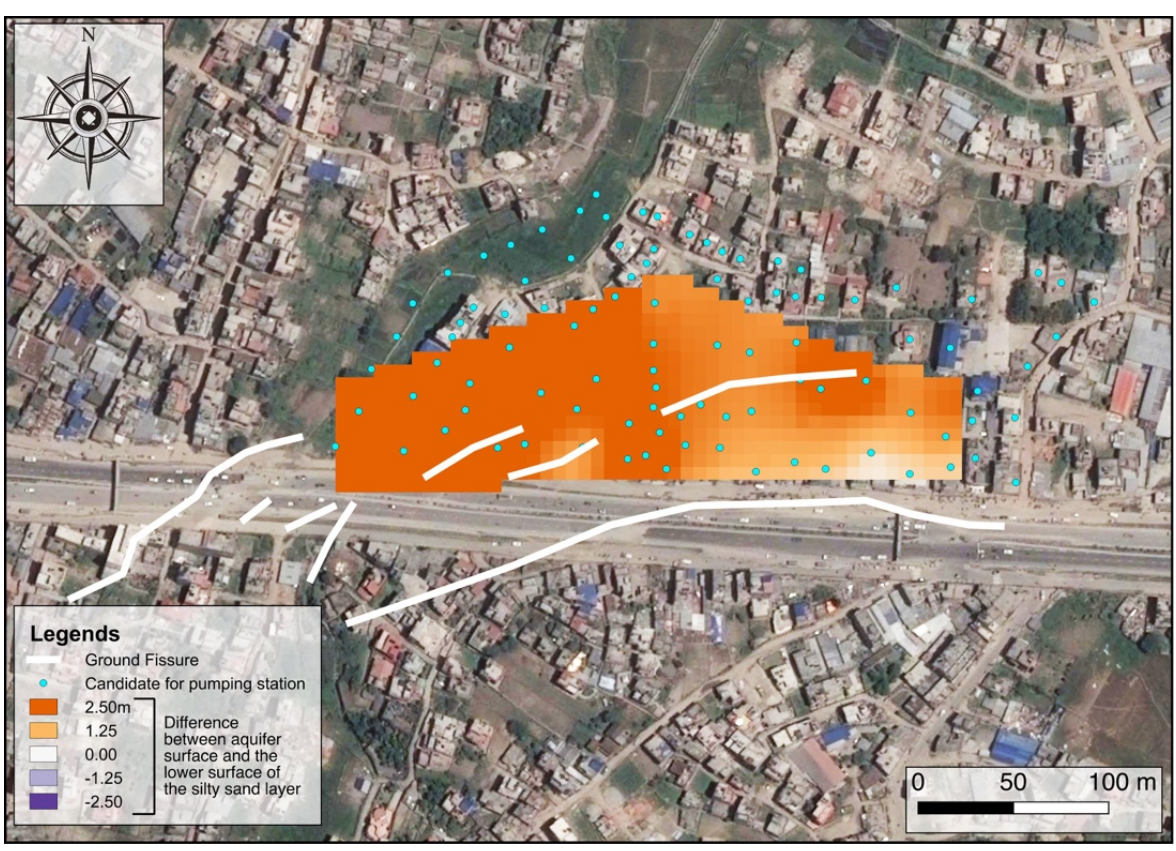

Fig. 9 Difference between the upper surface of the aquifer and the lower surface of the silty sand layer in Kausalter (before lowering groundwater level) 


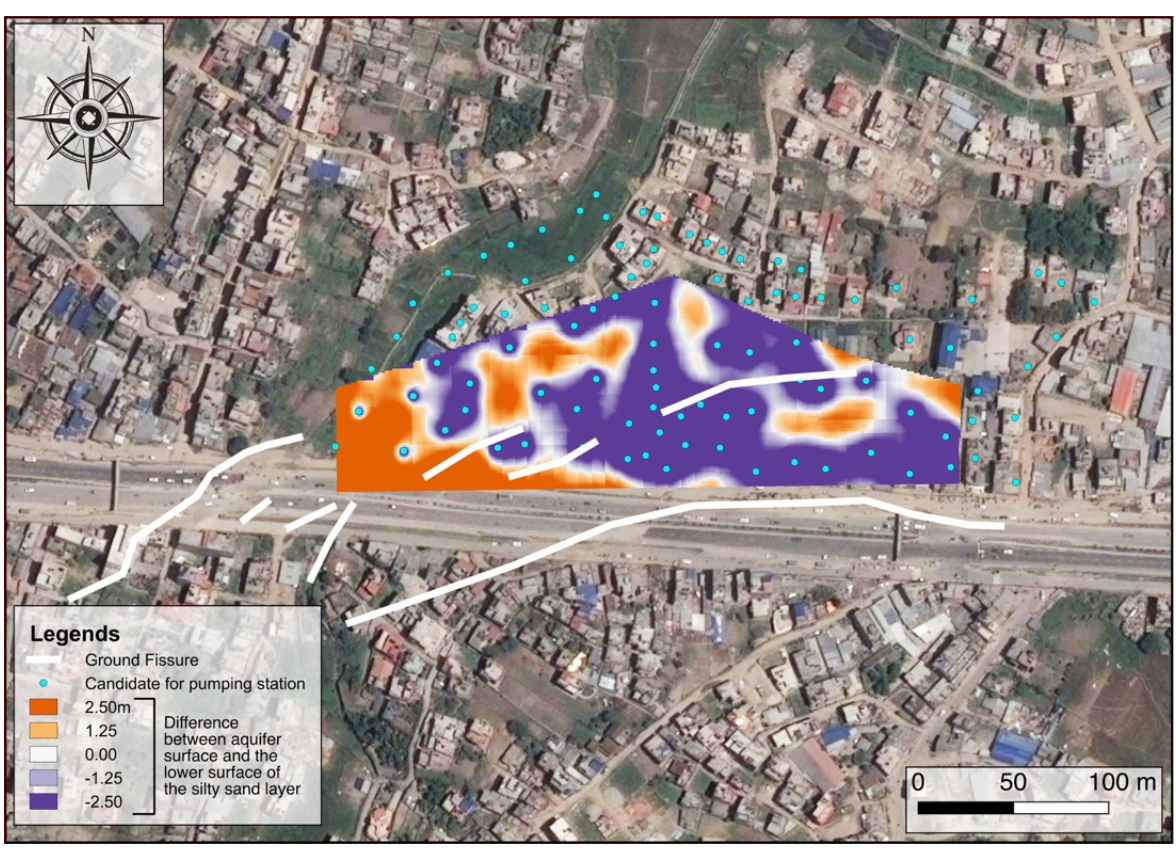

Fig. 10 Difference between the upper surface of the aquifer and the lower surface of the silty sand layer in Kausalter (After lowering groundwater level) 


\section{List of Tables}

1 Obtained ages of organic soils found at BH-7, BH-8, BH-9, and trench .................... 22 
Table 1 Obtained ages of organic soils found at BH-7, BH-8, BH-9, and trench

\begin{tabular}{|c|c|c|}
\hline Name & $\operatorname{Depth}(\mathrm{m})$ & Calibrated Age \\
\hline $\mathrm{BH}-7$ & $-1.83 \sim-1.90$ & BC $9538 \pm 217$ \\
\hline \multirow{4}{*}{ BH-8 } & $-5.32 \sim-5.43$ & BC $10583 \pm 108$ \\
\hline & $-5.44 \sim-5.50$ & BC $10215 \pm 211$ \\
\hline & $-5.65 \sim-5.78$ & BC $10042 \pm 157$ \\
\hline & $-5.81 \sim-5.97$ & BC $11181 \pm 65$ \\
\hline \multirow{2}{*}{ BH-9 } & $-2.84 \sim-3.00$ & BC $12815 \pm 309$ \\
\hline & $-3.20 \sim-3.40$ & BC $10364 \pm 203$ \\
\hline Trench & - & BC 9751士294 \\
\hline
\end{tabular}




\begin{tabular}{ll}
\hline Abbreviation & Meaning \\
\hline SPT & Standard Penetration Test \\
MASW & Multi-channel Analysis of Surface Wave \\
$M_{w}$ & Moment magnitude \\
KATNP & Kathmandu, Nepal observatory of the United States Geological \\
& Survey \\
$H$ & Horizontal components of ambient ground vibrations \\
$V$ & Vertical components of ambient ground vibrations \\
$V_{s}$ & Shear wave velocity \\
$h$ & Unconfined aquifer's saturated thickness \\
$r$ & Radial distance between the center of each well and a certain \\
& location where the unconfined aquifer's saturated thickness is \\
$h_{p}$ & reached during continuous pumping \\
$Q$ & Equilibrium water level in the well during pumping \\
$h_{b}$ & Volume of water pumped per unit time \\
$R$ & Equilibrium water level before pumping starts \\
& Influence radius beyond which the water level converges on the \\
$s$ & initial water level \\
$k$ & Height of drawdown \\
$D_{20}$ & Permeability coefficient \\
\hline
\end{tabular}

